\title{
Mudança do comportamento infantil diante do hábito de escovar os dentes
}

\author{
Infantile behavioral changes due to toothbrushing habits
}

Mariângela Monteiro de Melo*

Luiz Reynaldo de Figueiredo Walter **

\begin{abstract}
MELO, M. M.; WALTER, L. R. F. Mudança do Comportamento Infantil diante do Hábito de Escovar os
\end{abstract}
Dentes. Semina, Londrina, v. 18, ed. especial, p. 63-68, fev. 1997.

\begin{abstract}
RESUMO: O trabalho investiga as mudanças comportamentais dos bebês de 0 a 30 meses de idade e relaciona os diferentes padróes com a fase oral Pré-eruptiva e Pós-enuptiva. Foi verificado que a maioria das crianças, quando desdentadas, apresentam um comportamento positivo (Conduia " $D$ ") maior (76\%), e quando da erupção e início da limpeza existe uma mudança para pior no comportamento passando de $76 \%$ de conduta "D" para 45\%, havendo uma diminuição do predominio de conduta positiva.

Outro fator importante observado é que as mães relataram que as crianças são mais receptivas ao uso de escova e creme dental do que à limpeza com gaze e $\mathrm{H}_{2} \mathrm{O}_{2}$ diluída assim como relataram que as escovas dentais não são adequadas para as crianças nesta faixa etária, havendo necessidade de adequá-las para que isso não desestimule essas crianças diante do hábito de escovar os dentes.
\end{abstract}

PALAVRAS-CHAVE: Comportamento; Escovação Dental.

ABSTRACT: This work intends to investigate the behavioral changes of 0 to 30 months babies and to associate the different patterns to the pre and post-eruptive oral phase. It was verified that when children have no teeth, most part of them (76\%) have a positive behavior

$(D$ conduct) and when the eruption and cleaning procedures start there is a change for

* Autora: Aluna do $5^{\circ}$ ano de Graduaçăo em Odontologia da Universidade Estadual de Londrina.

**: Orientador; Livre-docente, Doutor em Odontopediatria/Professor Titular de Odontopediatria da Universidade Estadual de Londrina/Centro de Ciências da Saúderua Pernaunbuco, 54(1) - Fonc (1043) 321-20112 - CEP 86020-070) - Londrina - Paraná. 
worse, passing from $76 \%$ of $D$ conduct to $45 \%$, showing a decrease in the predominance of the positive conduct.

Another important factor verified was that mothers reported that the children are more receptive for the use of toothbrush and dentifrice than to the cleaning with gauze and dilute $\mathrm{H}^{2} \mathrm{O}^{2}$ (Hydrogen Peroxide) and they also reported that infantile toothbrushes are not adequate for children of these ages (0 to 30 months), existing the need of their adequacy to avoid that this fact deviates these children from their toothbrushing habits.

KEY WORDS: Behavior; Toothbrushing.

\section{INTRODUÇÃO}

Existem na literatura algumas escalas de definição do comportamento infantil, dentre estas, a de WRIGHT é uma das mais usadas e onde o comportamento varia de $\mathrm{A}$ a D (A negativo e D conduta positiva).

QUADRO 1 - Escala comportamental de Wright (1975)

\begin{tabular}{|c|c|c|}
\hline Símbolo & $\begin{array}{c}\text { Tipos de } \\
\text { Condutas }\end{array}$ & $\begin{array}{c}\text { Caracterização das } \\
\text { Condutas }\end{array}$ \\
\hline A & conduta negativa & $\begin{array}{l}\text {-recusa ao tratamento } \\
\text {-resistência e choro forte }\end{array}$ \\
\hline B & conduta indefinida & $\begin{array}{l}\text {-pequena resistência e } \\
\text { choramingo } \\
\text {-medo e nervosismo }\end{array}$ \\
\hline C & conduta satisfatória & -adaptação cautelosa e \\
& & $\begin{array}{l}\text { reserva ao tratamento } \\
\text {-pequena relutância }\end{array}$ \\
\hline D & conduta positiva & -bom relacionamento \\
& -interesse ao tratamento \\
\hline
\end{tabular}

Este quadro de condutas apresentado mostra que a conduta "A" é a conduta indesejada no consultório, a conduta $\mathrm{B}$ é a indefinida c pouco desejada enquanto a conduta "C e D" são as desejadas durante o atendimento, pois permite uma aproximação positiva.

Com base na literatura, a criança menor de 30 meses de idade passa por alguns períodos de desenvolvimento que caracterizam seu comportamento. De acordo com PIAGET (1919), um destes períodos denomina-se Sensório-motor e para FREUD (1936), este mesmo período denomina-se Fase Oral sendo que esta se subdivide em fase oral passiva ou de sucção (antes da erupção dos dentes) e fase oral ativa ou canibalesca (com o início da erupção dos dentes), onde a criança aprescniase bastante agressiva.

Na Odontologia para Bebês a atenção odontológica inicia-se neste período e sendo mais direcionada à educação dos pais e prevenção nos filhos (WALTER ct al, 1996), apresentando uma interrogação sobre as condutas dos bebês durante as consultas.

MELO E WALTER em 1994 evidenciaram que o atendimento precoce desperta o condicionamento contínuo e progressivo, onde as crianças se ambientam, aceitam e até se interessam pelo tratamento e NAKAMA e WALTER (1993) mostraram que a visita ao dentista já no primeiro ano de vida, é justificada, principalmente, pela manutenção da saúde bucal.

Com os tratamentos educativos/preventivos, a criança não tem contato com a dor e existe a tendência de que o seu comportamento evolua para melhor sem que ocorram traumas decorrentes de dor causada pela cárie (MELO e WALTER, 1994). Neste estudo, $80.6 \%$ das crianças pesquisadas apresentaram conduta positiva ou satisfatória ( $C$ ou $D$ ) na última consulta, enquanto que, no início do tratamento, $71 \%$ dos bebês apresentaram conduta negativa ou indefinida (A ou B), sem que fosse avaliado a presença ou não dos dentes. Interessa pois, aos odontopediatras, que com o decorrer do tratamento a 
TABELA 1 - Conduta inicial registrada nas fichas clínicas de 200 pacientes desdentados e após a erupção dentária, BebêClínica, 1996.

\begin{tabular}{|c|c|c|c|c|c|}
\hline $\begin{array}{l}\text { Conduta na Limpeza } \\
\text { com dente } \\
\text { limpeza sem dentes }\end{array}$ & $\begin{array}{c}\text { (\% com dente) } \\
\text { A } \\
(\% \text { sem dente })\end{array}$ & $\begin{array}{c}\text { (\% com dente) } \\
\text { B } \\
(\% \text { sem dente) }\end{array}$ & $\begin{array}{c}\text { (\% com dente) } \\
\mathrm{C} \\
\text { (\% sem dente) }\end{array}$ & $\begin{array}{c}\text { (\% com dente) } \\
\text { D } \\
(\% \text { sem dente) }\end{array}$ & $\begin{array}{l}\text { TOTAL } \\
\text { FINAL }\end{array}$ \\
\hline A & $\begin{array}{c}(48,2 \%) \\
14 \\
(26,4 \%)\end{array}$ & $\begin{array}{c}(20,6 \%) \\
6 \\
(10,5 \%)\end{array}$ & $\begin{array}{c}(20.6 \%) \\
6 \\
(10,4 \%)\end{array}$ & $\begin{array}{c}(10,3 \%) \\
3 \\
(7,14 \%)\end{array}$ & $\begin{array}{c}29 \\
(11,3 \%)\end{array}$ \\
\hline B & $\begin{array}{c}19,0 \%) \\
4 \\
(7,54 \%) \\
\end{array}$ & $\begin{array}{c}(57,1 \%) \\
12 \\
(21,0 \%) \\
\end{array}$ & $\begin{array}{c}(19,0 \%) \\
4 \\
(8,33 \%)\end{array}$ & $\begin{array}{c}(4,76 \%) \\
\mathbf{1} \\
(2,38 \%) \\
\end{array}$ & $\begin{array}{c}21 \\
(8 \%) \\
\end{array}$ \\
\hline $\mathrm{C}$ & $\begin{array}{c}(33,3 \%) \\
14 \\
(26,4 \%)\end{array}$ & $\begin{array}{c}(26,1 \%) \\
\mathbf{1 1} \\
(19,2 \%)\end{array}$ & $\begin{array}{c}(30,9 \%) \\
\mathbf{1 3} \\
(27,0 \%)\end{array}$ & $\begin{array}{c}(10,2 \%) \\
4 \\
(9,52 \%)\end{array}$ & $\begin{array}{c}42 \\
(19 \%)\end{array}$ \\
\hline $\mathrm{D}$ & $\begin{array}{c}(19,4 \%) \\
21 \\
(39,62 \%)\end{array}$ & $\begin{array}{c}(25,9 \%) \\
28 \\
(49,1 \%)\end{array}$ & $\begin{array}{c}(23,1 \%) \\
25 \\
(52,0 \%)\end{array}$ & $\begin{array}{c}(31,4 \%) \\
\mathbf{3 4} \\
(80,95 \%)\end{array}$ & $\begin{array}{c}108 \\
(62,6 \%)\end{array}$ \\
\hline TOTAL & $\begin{array}{c}\mathbf{5 3} \\
(26,5 \%)\end{array}$ & $\begin{array}{c}\mathbf{5 7} \\
(28,5 \%)\end{array}$ & $\begin{array}{c}48 \\
(24,0 \%)\end{array}$ & $\begin{array}{c}\mathbf{4 2} \\
(21,0 \%)\end{array}$ & 200 \\
\hline
\end{tabular}

criança se torne cooperativa, por isso o atendimento precoce é fundamental tanto para a manutenção da saúde bucal como para a adaptação da criança aos tratamentos odontológicos futuros (WALTER et al,1996).

\section{OBJETIVOS}

O presente trabalho busca observar a mudança do comportamento infantil em dois momentos. O primeiro, quando da erupção dos 10 dentes e os pais iniciam a limpeza com gaze e $\mathrm{H}_{2} \mathrm{O}_{2}$ destes dentes.

O segundo momento ocorre quando erupcionam os primeiros molares e se tem início o uso da escova e creme dental.

\section{MATERIAIS E MÉTODOS}

Este estudo consta de coleta de informações de 200 fichas do arquivo da Bebê-Clínica* e da análise das respostas de 132 mães a um questionário aplicado alcatoriamente em mães presentes na sala de espera da Bebê-Clínica, onde se observou as condutas destas

* Bebê-Clinica-Universidade Estadual de Londrina crianças durante os procedimentos de limpeza com $\mathrm{H}_{2} \mathrm{O}_{2}$ diluída e gaze quando se apresentam ainda sem dentes isto é, por volta dos 6 meses de idade média. Foi observado também suas condutas quando já se apresentam com dentes, mantendo-se ainda o procedimento de limpeza com $\mathrm{H}_{2} \mathrm{O}_{2}$ diluída e gaze, o que ocorre até por volta do 180 mês.

O último aspecto observado na coleta de dados das fïchas clínicas e nos questionários, foi a conduta no início do uso da escova e creme dental, o que se dá por volta de um ano e meio de idade ( 18 meses).

O Questionário foi aplicado a 132 mães que iniciaram a escovação em seus filhos, e foi previamente testado a fim de adequar as questões a serem analisadas.

\section{RESULTADOS E DISCUSSÃO}

PIAGET (1919) Apud DIAMANT (1989), afirma que o bebê passa por períodos variados de comportamento, onde cada um deles tem a sua conduta característica. A tabela I montra que $81,6 \%$ da população estudada apresentou conduta satisfatória ou positiva ( $\mathrm{C}$ ou D) quando esta ainda apresentava-se sem dentes (Período Sensório-motor), também chamada de fase oral passiva ou de sucção (FREUD, 1936). 
A tabela $I$ evidencia que, das fichas pesquisadas, $62,6 \%$ das crianças desdentadas apresentavam-se com conduta " $D$ ", porém com a erupção dos dentes e o início da limpeza ocorreu declínio desta conduta para $21 \%$ (tabela I) e, baseado nas informações das mães, esse percentual foi de $12,1 \%$ (figura 1 ), reafirmando o relato de FREUD em 1936, em relação à fase oral ativa ou canibalesca.

DOLTO (1988) relata que, com a presença dos dentes, o prazer que o bebê sentia se transforma em agressão e, de acordo com o questionário respondido pelas mães $(22,72 \%$ - figura I) e com a busca feito nas fichas (26.5\% - tabela I) as crianças tornam-se arredias à limpeza com a gaze e $\mathrm{H}_{2} \mathrm{O}_{2}$.

Com base nas informações do firgura $\mathbb{1}, 84,8 \%$ das mães perceberam que a criança com idade superior a 18 meses, alćm de apresentarem-se agressivas durante a limpeza com gaze e $\mathrm{H}_{2} \mathrm{O}_{2}$ diluída, se interessam por atitude que são realizadas pelos adultos, deste modo elas sentem-se mais amadurecidas, mostrando aos pais que estão se ajustando aos seus costumes (DOLTO, $1988 \mathrm{e}$ KLATCHOIAN, 1991). Uma das primeiras primeiras manifestações deste interesse, é pelo hábito de escovação dentária executado pelos adultos e/ou irmãos maiores, ficando a criança por perto quando estes a executam e pedindo para que escovem seus dentes. Quando da introdução deste hábito, $54,84 \%$ das mães relatam uma melhora no comportamento de seu filho (figura II).

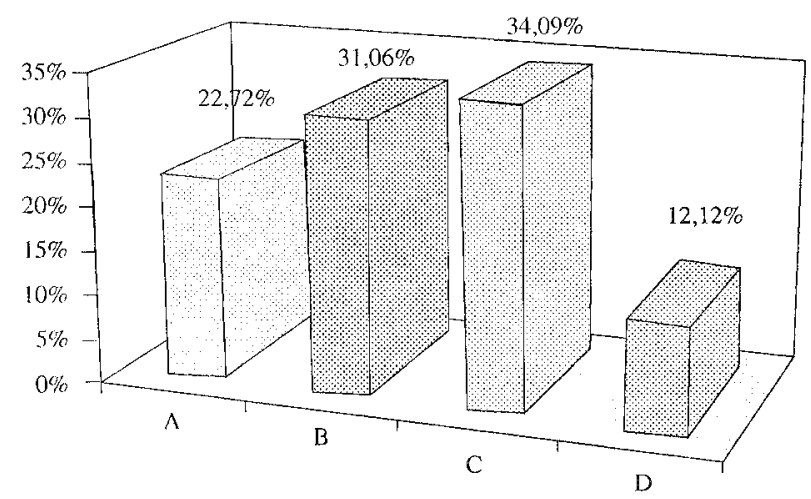

FIGURA 1 - Conduta relatada pelas mães durante a limpeza com $\mathrm{H}^{2} \mathrm{O}_{2}$ na presença dos dentes (Bebê Clínica, 1996)

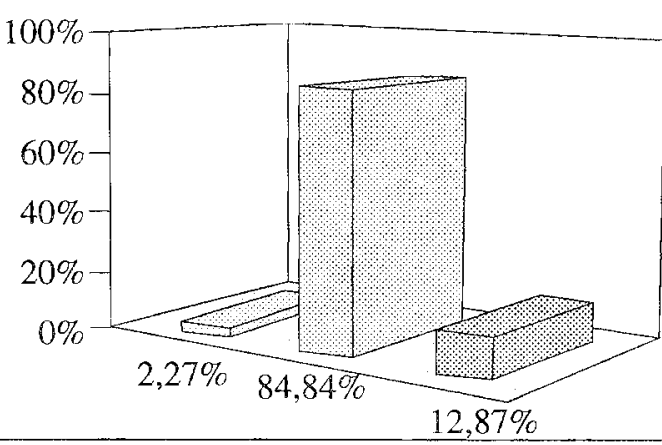

Não se interessa

- Fica por perto e pede para escovar os dentes

. Fica por perto mas não pede para escovar os dentes

FIGURA 2 - Respostas das mães à pergunta: como seu filho reage quando as pessoas de sua casa esião escovando os dentes? (Bebê Clínica, 1996)

A figura III mostra que, de acordo com as fichas, ocorre mudança do comportamento infantil para melhor, quando se introduz o uso da escova e creme dental, indicando que a escovação é melhor aceita pelos bebês do que a limpeza de seus dentes e, que, 9,52\% das crianças que se apresentavam com conduta "D" após a erupção dentária, pioraram seu comportamento durante a prática da escovação. Ainda com base na figura III, pode-se notar que ocorre mudança do comportamento infantil em dois momentos: um, quando se inicia a erupção dos dentes e ela torna-se arredia à higienização, outro quando se introduz o hábito de escovar os dentes, e sua conduta muda novamente para positiva (D).

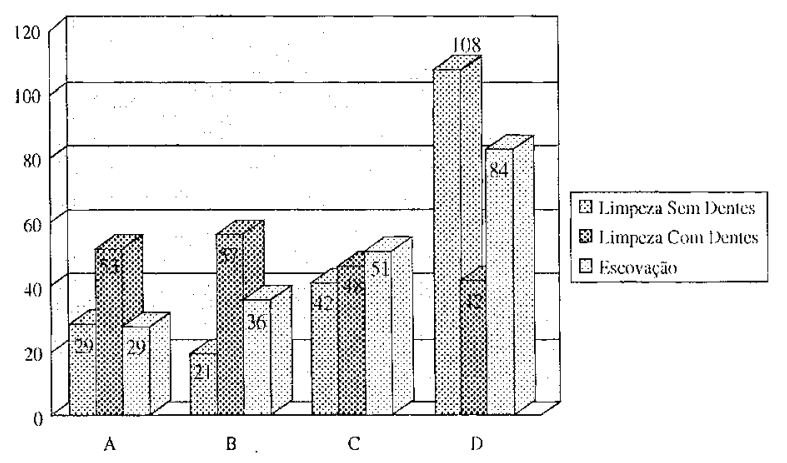

FIGURA 3 - Comparação das condutas dos bebês nos 3 períodos analisados (Bebê-Clínica, 1996) 
Foi abordado no questionário aplicado às mães, o tipo de escova utilizada na escovação dos dentes de seus filhos (figura IV) e $56 \%$ utilizavam qualquer escova infantil e $11,36 \%$ utilizavam escova própria para bebês. De acordo com este relato, embora as escovas sejam infantis, as mães consideraram inadequadas para o uso em seus bebês, uma vez que as marcas comerciais cxistentes no mercado brasileiro não suprem as necessidades de escovas dentais para menores de 30 meses.

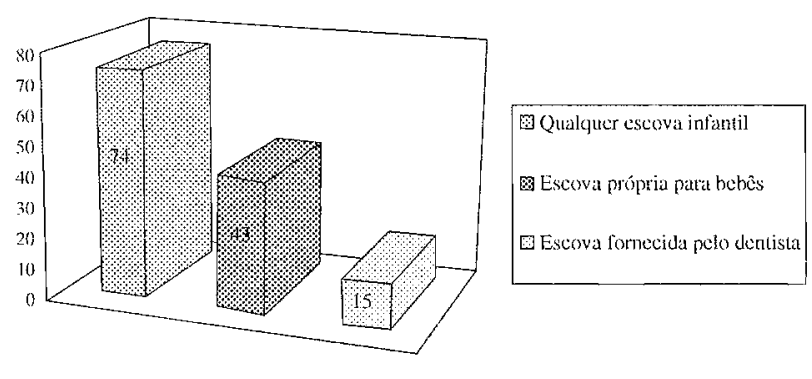

FIGURA 4 - Resposta das mães à pergunta à pergunta: Que tipo de escova dental você usa em seu filho? (BebêClínica, 1996)
Observando a tabela II (fichas clínicas) e o figura V (informações das mães) é possível verificar que a conduta positiva ou satisfatória durante a escovação, foi de $67,5 \%$ e $59,84 \%$ respectivamente, mostrando que a escovação dental nas crianças menores de 30 meses, foi bem aceita, mesmo que ela ainda se encontre na fase oral ativa ou canibalesca, preferindo esta prática à de limpeza com $\mathrm{H}_{2} \mathrm{O}_{2}$ diluída e gaze.

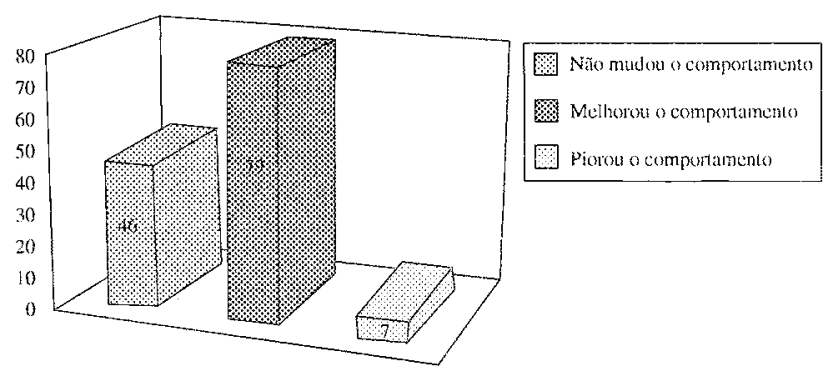

$\mathbb{F}$ IUUR 5 - Conduta relatada pela mãe após a introdução do uso de escova e creme dental em seu filho (Bebê-Clinica, 1996)

TABELA 1 - Conduta inicial registrada nas fichas clínicas de 200 pacientes desdentados e após a erupção dentária, BebêClínica, 1996.

\begin{tabular}{|c|c|c|c|c|c|}
\hline Conduta na & $\begin{array}{c}\text { (\% com dente) } \\
\text { (\% sem dente) }\end{array}$ & $\begin{array}{c}\text { (\% com dente) } \\
\text { (\% } \\
\text { (\% sem dente) }\end{array}$ & $\begin{array}{c}\text { (\% com dente) } \\
\mathbb{C} \\
(\% \text { sem dente) }\end{array}$ & $\begin{array}{c}\text { (\% com dente) } \\
\text { D } \\
(\% \text { sem dente) }\end{array}$ & $\begin{array}{l}\text { TOTAL } \\
\mathbb{F} \amalg \mathbb{N A L}\end{array}$ \\
\hline A & $\begin{array}{c}(48,2 \%) \\
14 \\
(26,4 \%)\end{array}$ & $\begin{array}{c}(20,6 \%) \\
9 \\
(10,5 \%)\end{array}$ & $\begin{array}{c}(20,6 \%) \\
15 \\
(10,4 \%)\end{array}$ & $\begin{array}{c}(10,3 \%) \\
16 \\
(7,14 \%)\end{array}$ & $\begin{array}{c}53 \\
(26.5 \%)\end{array}$ \\
\hline B & $\begin{array}{c}(19,0 \%) \\
6 \\
(7,54 \%)\end{array}$ & $\begin{array}{c}(57,1 \%) \\
13 \\
(21,0 \%)\end{array}$ & $\begin{array}{c}(19,0 \%) \\
\mathbb{1} \% \\
(8,33 \%)\end{array}$ & $\begin{array}{c}(4,76 \%) \\
22 \\
(2,38 \%)\end{array}$ & $\begin{array}{c}57 \\
(28,5 \%)\end{array}$ \\
\hline $\mathrm{C}$ & $\begin{array}{c}(33,3 \%) \\
6 \\
(26,4 \%)\end{array}$ & $\begin{array}{c}(26,1 \%) \\
9 \\
(19,2 \%)\end{array}$ & $\begin{array}{c}(30,9 \%) \\
10 \\
(27,0 \%)\end{array}$ & $\begin{array}{c}(10,2 \%) \\
23 \\
(9,52 \%)\end{array}$ & $\begin{array}{c}48 \\
(19 \%)\end{array}$ \\
\hline D & $\begin{array}{c}(19,4 \%) \\
3 \\
(39,62 \%)\end{array}$ & $\begin{array}{c}(25,9 \%) \\
5 \\
(49,1 \%)\end{array}$ & $\begin{array}{c}(23,1 \%) \\
11 \\
(52,0 \%)\end{array}$ & $\begin{array}{c}(31,4 \%) \\
23 \\
(80,95 \%)\end{array}$ & $\begin{array}{c}42 \\
(62,6 \%)\end{array}$ \\
\hline TOTAL & $\begin{array}{c}29 \\
(14,5 \%)\end{array}$ & $\begin{array}{c}36 \\
(18,0 \%)\end{array}$ & $\begin{array}{c}51 \\
(25,5 \%)\end{array}$ & $\begin{array}{c}84 \\
(42,0 \%)\end{array}$ & 200 \\
\hline
\end{tabular}




\section{CONCLUSÕES}

1. As crianças, quando sem dentes, a conduta que prevalece é a positiva (D) com $54 \%$ dos casos estudados.

2. Com o inicio da limpeza com $\mathrm{H}_{2} \mathrm{O}_{2}$ diluída e gaze, a tendência das crianças é de piorar a conduta apresentando conduta negativa ou indefinida ( $\mathrm{A}$ ou $\mathrm{B}$ ), e isso ocorreu em $55 \%$ dos casos.

3. As crianças maiores de 18 meses e menores de 30 mescs, prefercm o uso da cscova e creme dental à limpeza com gaze e $\mathrm{H}_{2} \mathrm{O}_{2}$ diluída, realizada até os 18 meses em $84,84 \%$.

4. É preciso iniciar o uso de escova e creme dental nos menores desde o início da erupção da dentadura decídua, aproveitando o seu interesse em tal tarefa.

5. Faz-se necessário adequar as escovas dentais infantis para os menores de 30 meses, para que o uso não implique em desconforto à criança, desestimulando-a.

Este trabalho recebeu Menção Honrosa na Universidade Estadual de Londrina para concorrer ao $\sigma^{\circ}$ Prêmio Estínulo Kolynos

\section{REFERÊNCIAS BIBLIOGRÁFICAS}

BENGTSON, N. G.; BENGTSON, A. L.; PICCININI, D.P. Erupção dos dentes decíduos: Sintomas gerais apresentados. Rev Gaucha Odont, v.36, n.3, p.401-5, nov/dez. 1988.

DARGARSSIES, S. SAINT-ANNE - As Bases do desenvolvimento do lactente. São Paulo: Manole, $1980-1-243 p$.

DOLTO, F. Psicanálise e Pediatria. Rio de Janeiro, Guanabara, 1988. 261p.
FREUD, A. (1936) apud SPITZ, R. A.- O primeiro ano de vida: um estudo psicanalítico do desenvolvimento normal e anômalo das relações objetais. São Paulo: Martins Fontes, 1991. 265p.

GESEL. A; AMATRUDA. C.S. Diagnóstico do desenvolvimento- Avaliação e tratamento do desenvolvimento neuropsicológico no lactente $e$ na criança pequena- o normal e o patológico. Rio de janeiro: Harper tradução, Livraria Atheneu, 1990. 125p.

KLATCHOIAN, D. A- Psicologia Odontopediátrica. São Paulo: Sarvier, 1991.

MELO,M.M.; Walter.L.R.F. Estudo da relação comportamental da criança com a erupção dentária. In: Congresso Universitário Brasileiro de Odontologia. São Paulo, 05-09 Set. 1995. Anais. 1995, p.13.

MELO,M.M.; Walter.L.R.F. Relação comportamental em bebês de 0 a 30 meses. In: Congresso Universitário Brasileiro de Odontologia. São Paulo, 05-09 Set. 1995. Anais. 1995, p.03.

MUSSEN, P. H; J.J. KAGAN,J; Desenvolvimento $e$ personalidade da criança. São Paulo: Habra, 1977. 24- 54p.

NAKAMA, R; WALTER,L.R.F . Prevention of dental caries in first year of life. J. Dent Res, v.73, n.4, p.773, Apr. 1993.

PIAGET,J. ( 1919) apud Diamant;A. Cypcl; S. Neurologia Infantil-Lefèvre-Rio de Janeiro: Atheneu, 1989. 111-126p.

WALTER, L. R. F; FERELLE, A; ISSAO, M. Odontologia para o bebê. São Paulo: Artes Médicas, 1996.

WRIGHT,G,Z.; Behaviour Managenent. Philadelphia, W.B.Saunders, 1975. 